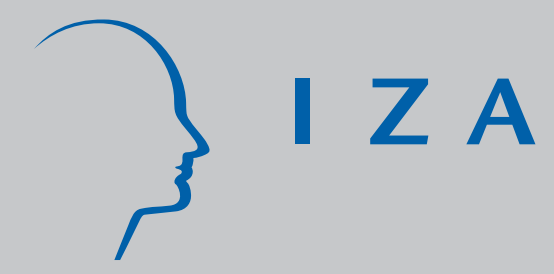

IZA DP No. 3914

Who Makes a Good Leader?

Social Preferences and Leading-by-Example

Simon Gächter

Daniele Nosenzo

Elke Renner

Martin Sefton

December 2008 


\title{
Who Makes a Good Leader? Social Preferences and Leading-by-Example
}

\author{
Simon Gächter \\ University of Nottingham \\ and IZA
}

Daniele Nosenzo

University of Nottingham

Elke Renner

University of Nottingham

Martin Sefton

University of Nottingham

\section{Discussion Paper No. 3914 \\ December 2008}

\author{
IZA \\ P.O. Box 7240 \\ 53072 Bonn \\ Germany \\ Phone: +49-228-3894-0 \\ Fax: +49-228-3894-180 \\ E-mail: iza@iza.org
}

Any opinions expressed here are those of the author(s) and not those of IZA. Research published in this series may include views on policy, but the institute itself takes no institutional policy positions.

The Institute for the Study of Labor (IZA) in Bonn is a local and virtual international research center and a place of communication between science, politics and business. IZA is an independent nonprofit organization supported by Deutsche Post World Net. The center is associated with the University of Bonn and offers a stimulating research environment through its international network, workshops and conferences, data service, project support, research visits and doctoral program. IZA engages in (i) original and internationally competitive research in all fields of labor economics, (ii) development of policy concepts, and (iii) dissemination of research results and concepts to the interested public.

IZA Discussion Papers often represent preliminary work and are circulated to encourage discussion. Citation of such a paper should account for its provisional character. A revised version may be available directly from the author. 
IZA Discussion Paper No. 3914

December 2008

\section{ABSTRACT \\ Who Makes a Good Leader? Social Preferences and Leading-by-Example}

We examine the effects of social preferences and beliefs about the social preferences of others in a simple leader-follower voluntary contributions game. We find that groups perform best when led by those who are reciprocally oriented. Part of the effect can be explained by a false consensus effect: selfish players tend to think it more likely that they are matched with another selfish player and reciprocators tend to think it more likely that they are matched with another reciprocator. Thus, reciprocators contribute more as leaders partly because they are more optimistic than selfish players about the reciprocal responses of followers. However, even after controlling for beliefs we find that reciprocally-oriented leaders contribute more than selfish leaders. Thus, we conclude that differing leader contributions by differing types of leader must in large part reflect social motivations.

JEL Classification: A13, C92, D03

Keywords: reciprocity, contribution preferences, leadership, leading-by-example, false consensus effect

Corresponding author:

Simon Gächter

CeDEx

School of Economics

Sir Clive Granger Building

University Park

Nottingham NG7 2RD

United Kingdom

E-mail: simon.gaechter@nottingham.ac.uk 
"Then I would look for integrity. A leader sets an example, especially a strong leader. He or she is someone on whom people ... in the organization model themselves." Peter Drucker on Picking a Leader, excerpted from "The Daily Drucker" (p. 5, Drucker (2004)).

\section{Introduction}

One of the challenges facing leaders is how to get followers to do something they otherwise would not do. In settings where followers are tempted to free-ride on the contributions of others, the challenge is for leaders to somehow induce followers to eschew their narrowly-defined personal interests in order to promote the wider interests of the group. Such settings are commonplace in the workplace, and also in political and military organizations. One mechanism by which a leader may influence her followers is through leading-by-example. Recent research has shown that followers respond strongly to the example set by a leader (Gächter and Renner (2003), (2007); Moxnes and van der Heijden (2003); Güth, et al. (2007); Levati, et al. (2007); Potters, et al. (2007)).

In this paper we study leader-follower behaviour and focus on the question of who makes the best leader. Our framework is a simple leader-follower game in which efficiency and selfinterested behaviour are in conflict. More specifically, we study a sequential voluntary contributions game where each player has an endowment and can choose how much of this to contribute to a project. Joint earnings are maximised when each player contributes their full endowment, but if subjects are maximise own-earnings they have incentives to contribute nothing.

Previous experiments with this type of game show that subjects do make positive contributions, but at the same time contributions fall short of efficient levels. Moreover, there is substantial heterogeneity in decisions across subjects in both roles. Among followers, some maximize own earnings but others contribute substantial amounts. Moreover, follower contributions are heavily influenced by leader contributions. In experiments with sequential prisoner's dilemmas second movers often cooperate if the first mover cooperates, but hardly ever if the first mover defects (Clark and Sefton (2001)), and in experiments with sequential contributions to a public good followers contributions tend to increase with leaders contributions (Gächter and Renner (2003), (2007)). Thus, cooperative behaviour by followers is often described as evidence of reciprocation or conditional cooperation (Keser and van Winden (2000); Fischbacher, et al. (2001)).

The experiments also reveal variability in leader decisions. Some leaders contribute nothing, almost certainly leading the group toward the lowest possible joint earnings. Other leaders contribute large amounts. If matched with a reciprocator this leads to high joint earnings, but there 
is also the possibility of being suckered when matched with a self-interested player. Compared with follower decisions, it is more difficult to interpret leader decisions. If a person contributes a lot in the role of leader is it because they are somehow 'pro-socially' inclined, or simply because they are self-interested but optimistic about the prospects of meeting a reciprocator? If a person contributes nothing is it because they are selfish, or are they a reciprocator who is pessimistic about the prospects of meeting another reciprocator? And, what type of player is likely to set a better example as a leader?

To answer these questions we present a new experiment in which decisions were elicited using a strategy method and subjects played in both roles. Using decisions in the role of follower we are able to classify players according to the degree of reciprocity they exhibit. Correlating these measures with their own decisions in the role of leader allows a within-subject crosstabulation of leader-contribution against follower type. Thus we are able to answer whether reciprocators make better or worse leaders. In order to answer whether differences between leader decisions reflect differing underlying social motivations or differing expectations about the follower we also have subjects predict what their opponent will do in the role of a follower. These predictions are used to gauge how optimistic subjects are about the chances of meeting a reciprocator, and we then ask whether leadership decisions vary across follower types controlling for this degree of optimism. That is, we ask whether optimistic reciprocators or optimistic selfinterested players make better leaders.

From their follower decisions we classify about a half of our subjects as selfish and about a half as reciprocating to some degree. In the role as leader we find that reciprocators contribute substantially more than selfish subjects. Although several variables help predict leader decisions for example men contribute more than women, and economists contribute less than noneconomists - the most useful variable for explaining leader contributions is their degree of reciprocity. We find that part (roughly, half) of the difference between the leader contributions of "Selfish" and "Strong Reciprocators" can be attributed to their differing beliefs. Selfish subjects tend to expect they will be paired with another Selfish subject and thus contribute little, whereas Strong Reciprocators expect to be paired with another Strong Reciprocator and so contribute more. Even so, after controlling for beliefs Strong Reciprocator leaders still contribute substantially more than Selfish leaders. Thus, we conclude that differing leader contributions by differing types of leader must in large part reflect social motivations. Furthermore, groups perform best when led by those who are reciprocally oriented.

The remainder of the paper is organized as follows. In the next Section we describe our experimental design and procedures. Section 3 presents our results. We offer concluding comments in Section 4. 


\section{Design and Procedures}

\subsection{The experimental game}

Our experiment is based on a simple two-player leader-follower game. Each player is endowed with 5 tokens, and must decide how many to contribute to a joint project. Leaders move first and their contribution decision is revealed to the Follower before the Follower chooses his own contribution. After the Follower's choice, the game ends and players' earnings are determined. For each token contributed to the project both players receive $£ 1$, and for each token not contributed to the project that player receives $£ 1.50$. Thus, player $i$ 's earnings are given by

$$
\pi_{i}=1.5 \cdot\left(5-c_{i}\right)+c_{i}+c_{j}
$$

where $c_{i}, c_{j} \in\{0,1,2,3,4,5\}$ represent the contribution decisions of player $i$ and $j$, for $i, j \in\{$ Leader, Follower $\}$ and $i \neq j$.

In our experiment subjects made decisions both in the role of Leader and Follower. Follower's decisions were elicited using the strategy method (Selten (1967)), i.e. they had to specify complete strategies in the game-theoretic sense. Thus, participants in our experiments were asked to make in total seven contribution decisions: one contribution decision in the role of Leader and six contribution decisions in the role of Follower, one for each possible contribution by the Leader. Only after all decisions had been made were subjects assigned a role in the experiment and paid according to the decisions they made in that role: with probability one half they were assigned the role of Leader and with probability one half the role of Follower. Hence, all seven contribution decisions were elicited using monetary incentives.

Subjects also had to complete a "Prediction Task". In this task subjects were asked to predict the contribution decisions that the other person in their group had made in the role of Follower. Thus subjects made six point predictions, one for each contribution decision their opponent made in the role of Follower. Subjects earned $£ 0.50$ for each correct prediction.

We implemented a one-shot version of this experimental game. In describing the game to subjects we did not use the labels "Leader" and "Follower", but rather we referred to "First Movers" and "Second Movers". For further details see the experimental instructions reproduced in the Appendix.

Basic demographic information was collected through a short post-experimental questionnaire that subjects filled out immediately after having submitted their decisions. To measure and control for inherent predisposition to self-interested behaviour we also employ the Machiavellian instrument (Christie and Geis (1970)), a psychometric test consisting of 20 
statements - such as "anyone who completely trusts anyone else is asking for trouble" or "it is hard to get ahead without cutting corners here and there" - to which subjects are asked to agree or disagree using a 7-level Likert scale. Those who tend to agree with the statements score higher on the Machiavellian instrument, signalling a combination of selfishness, cynicism about human nature and manipulativeness.

\subsection{Discussion of the design}

Our main interest lies in exploring the relation between subjects' leader-contributions, their own cooperation preferences and their expectations about others' cooperation preferences. We measure subjects' cooperation preferences by the degree of reciprocity they exhibit in their follower-contribution response to the Leader's contribution decisions. Note that the Follower decision directly determines the distribution of earnings and thus provides a clearer measure of cooperation preferences than Leader decisions. It is possible that a Leader may contribute not because they are inherently cooperative, but rather because they expect a reciprocal response that makes contributing pay. In order to measure a Follower's degree of reciprocity we need to observe a follower's response to different possible leader-contribution decisions. ${ }^{1}$ The use of the strategy method allows us to observe subjects' follower-contribution responses conditional on each possible leader-contribution decision without either resorting to repeated play (which might induce strategic confounds) or using deception. Thus, from each subject we elicit in an incentive compatible way a complete vector of conditional contribution decisions that we then use to classify subjects into “cooperation types” according to their revealed reciprocity.

Letting subjects play in both roles of the game allows us to correlate subjects' cooperation preferences (measured, as explained, by their conditional contribution decisions) with their (unconditional) contribution decision in the role of Leader. Thus, we can observe a within-subject cross-tabulation of leader-contribution against follower cooperation types that allows us to explore whether more cooperative types make better or worse Leaders.

Since we are also interested in how subjects' beliefs about others' cooperation preferences relate with their leader-contributions and their cooperation types, in our experiment we also have subjects predict what their opponent will do in the role of Follower. That is, from each subject we elicit a vector of predicted conditional contribution decisions. This allows us to measure how optimistic subjects are about the cooperation preferences of the players they are matched with. Subjects were given monetary incentives for correct prediction of others' contributions and could

\footnotetext{
${ }^{1}$ For example, observing a Follower that contributes zero tokens in response to a leader-contribution of zero tokens does not reveal whether the subject is motivated by reciprocity (and hence respond with unkindness to unkind leaderdecisions) or by self-interested profit maximisation. What we need to observe is the follower's contribution in different subgames.
} 
earn up to $£ 3$ from the Prediction Task. ${ }^{2}$ Note that the incentives are to predict the most likely response to each possible leader contribution. ${ }^{3}$

\subsection{Experimental procedures}

The experiment was conducted at the University of Nottingham in autumn 2008 using subjects recruited from a university-wide pool of students who had previously indicated their willingness to be paid volunteers in decision-making experiments. ${ }^{4}$ Six sessions were conducted, four sessions with 18 participants, one with 16 participants and one with 14 participants: thus, 102 subjects participated in total. The average age was 19.7 years and 55\% were male. No subject took part in more than one session.

All sessions used an identical protocol. Upon arrival, subjects were welcomed and randomly seated at visually separated computer terminals. Subjects were then given a written set of instructions that the experimenter read aloud. The instructions included a set of control questions about how choices translated into earnings. Subjects had to answer all the questions correctly before the experiment could continue.

The decision-making phase of the session consisted of three tasks: two decision tasks and the prediction task. The three tasks were presented to subjects on a single screen and they could complete them in any order they liked. ${ }^{5}$ In the two decision tasks subjects were asked to make contribution decisions both in the role of Leader and in the role of Follower. Subjects were informed at the beginning of the experiment that they would have had to make contributions decisions in both roles and that only after all decisions had been made would they have been informed of their actual role. All decisions were made anonymously, and neither during nor after the experiment were subjects informed about the identity of the other person in their group. Once everyone in the room had completed the three tasks subjects were informed of their role. Decisions and predictions were then implemented and subjects paid accordingly.

Subject earnings ranged from $£ 6.00$ to $£ 15.00$, averaging $£ 9.39$ (at the time of the experiment $£ 1=\$ 1.50$ ). On average the experimental sessions lasted about 50 minutes, including the completion of a post-experimental questionnaire and the payments.

\footnotetext{
${ }^{2}$ While there is no definite evidence that providing incentives when eliciting beliefs affects subjects' behaviour in the decision task of an experiment, it is generally recognised that such incentives increase the accuracy of the estimates, reducing the amount of "noise” in the data (see, for example, Gächter and Renner (2006)). See Blanco, et al. (2008) for a recent discussion of the literature.

${ }^{3}$ In order to elicit subjective probability distributions over possible responses in an incentive compatible manner subjects would have had to complete a 6x6 matrix, and we would have had to use a different scoring rule. We used the simpler prediction task to keep the task manageable for subjects.

${ }^{4}$ Subjects were recruited through the online recruitment system ORSEE (Greiner (2004)). The experiment was programmed and conducted with the software z-Tree (Fischbacher (2007)). The experimental software is available upon request.

${ }^{5}$ A screenshot of the Decision Screen was distributed to subjects with the experimental instructions and is reproduced in the Appendix.
} 


\section{Data analysis}

The following analysis of data is structured around our main research questions: What type of player makes the best Leader? And, do different Leader contributions reflect differing underlying social motivations, or differing expectations about the Follower? To explore these questions:

i. We first classify subjects according to their cooperation preferences, measured by the degree of reciprocity they exhibit in their follower-contribution responses.

ii. We then explore the relation between subjects' cooperation preferences and their (unconditional) contributions decisions as Leaders. Thus we will be able to answer whether more cooperative types make better or worse Leaders.

iii. In a third step, we ask whether subjects' preferences are systematically related to their beliefs about the preferences and behaviour of others. If this is indeed the case, we also explore whether such differences in beliefs are related to differences in Leaders' unconditional contribution decisions.

\subsection{Expressed Cooperation Preferences and Cooperation Types}

We measure subjects' cooperation preferences using their conditional contribution decisions in the role of Follower. Selfish (S) subjects are those who, in the role of Follower, contribute nothing irrespective of the Leader's contribution. 47 of our 102 subjects fall into the $\mathrm{S}$ category. The remaining 55 subjects are classified into three different cooperation types according to the following criterion. For each subject we computed how a (hypothetical) self-interested Leader would best-respond to the vector of conditional contribution decisions submitted by the subject. ${ }^{6}$ If even a self-interested Leader would contribute her entire endowment as a best-response to the subject's vector of conditional contributions, we conclude that the subject must exhibit a strong degree of reciprocity in his or her conditional contribution responses. We classify such a subject as a Strong Reciprocator (SR). 27 of our subjects fall into this category. If a self-interested Leader would find it optimal to contribute some, but not all, of her tokens as a best-response to a subject's vector of conditional contributions, the subject is classified as a Weak Reciprocator (WR). 22 of the subjects can be classified as WR. Finally, if a subject submitted a vector of contributions that contains positive contributions in response to some of the Leader's contributions, but does not give any incentive to a self-interested Leader to contribute any token to the project, we classify the subject as a Non-Reciprocator (NR). Only 6 subjects fall into this category ${ }^{7}$.

\footnotetext{
${ }^{6}$ Should the Leader be indifferent between two or more contribution decisions, the largest contribution is used for computing the Leader's best-response.

${ }^{7}$ Half of these NR subjects are "unconditional co-operators" who contribute the same (non-zero) amount irrespective of the Leader's contribution. The remaining 3 NR subjects contribute 1 or 2 tokens only if the Leader contributes 4 or 5 tokens.
} 
Figure 1 depicts - both separately for each preference type and aggregate across types - the average contribution decisions subjects made in the role of Follower as a function of the contribution level by the Leader ${ }^{8}$.

Figure 1. Average Follower Contribution

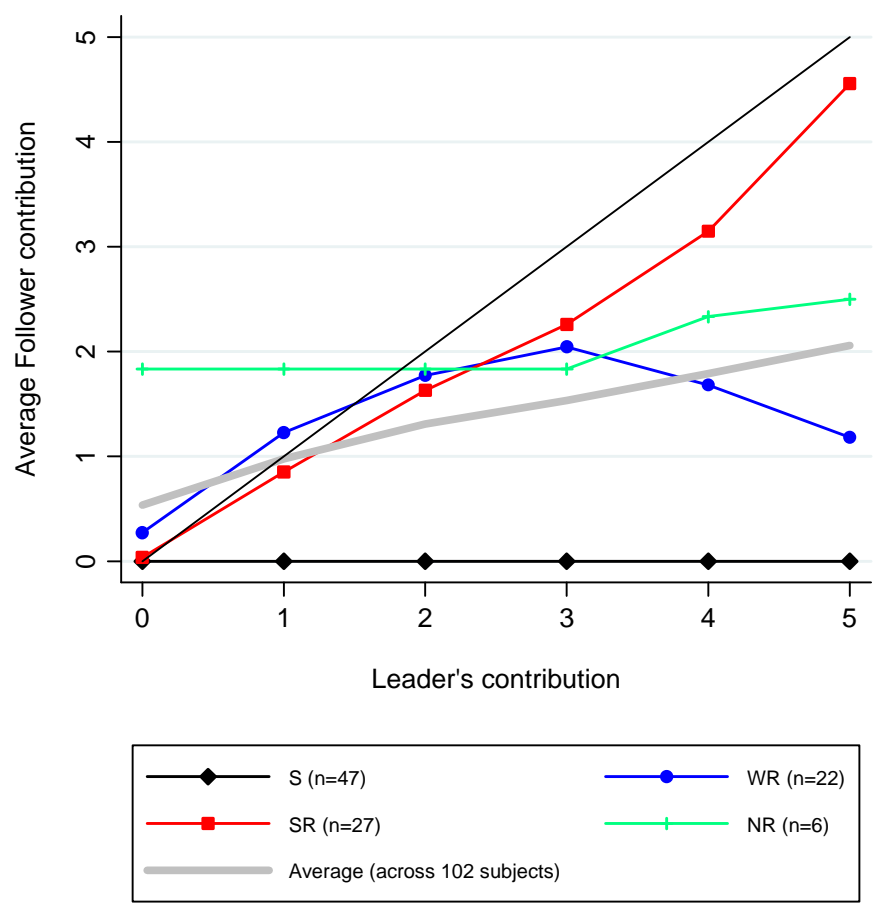

\subsection{Which cooperation type makes a better Leader?}

We next move to the analysis of the relation between subjects' cooperation preferences and their contribution decisions as Leaders.

Figure 2 plots the average leader-contribution decisions separately for the three major preference types. ${ }^{9}$ SR Leaders are those who contribute most to the public good (about 2.8 tokens on average), while S Leaders contribute on average least (slightly more than 0.5 tokens on average). WR Leaders' contribution decisions fall midway between the contributions of S and SR Leaders.

\footnotetext{
${ }^{8}$ Note that the patterns of contribution decisions of S, SR, WR and NR subjects closely resemble the average contribution patterns typically found in linear public goods games for "Free Riders", “Conditional Cooperators", Triangle Contributors" and “Others” according to the classification system introduced by Fischbacher, et al. (2001). In fact the two classification systems are highly consistent with one another: all S and NR subjects would be classified as Free Riders and Others respectively, 85\% of SR subjects as Conditional Cooperators, and 64\% of WR subjects as Triangle Contributors.

${ }^{9}$ In the remainder of the paper we will focus our analysis on the three major groups and ignore the subjects we classified as NR. Because these subjects represent only the $6 \%$ of our sample, we would not be able to draw any valid inference from their behaviour and their inclusion in the analysis would only unnecessarily complicate the exposition of our results. Any inference based on the restricted sample can also be derived using the whole sample of 102 subjects, unless otherwise stated.
} 
We can strongly reject the hypothesis that types contribute similar amounts (Kruskal-Wallis test: $\left.\chi^{2}(2 d . f)=38.65,. p<0.001\right)$. Pair-wise Mann-Whitney-U-tests reveal that $\mathrm{S}$ Leaders' contributions differ significantly both from SR and WR Leaders' contributions ( $z=5.605, p<0.001$ and $z=4.575, p<0.001$ respectively). The difference between SR and WR Leaders is smaller, but still significant at the $5 \%$ level $(z=2.065, p=0.039)$.

Figure 2. Average Contribution in the Role of Leader

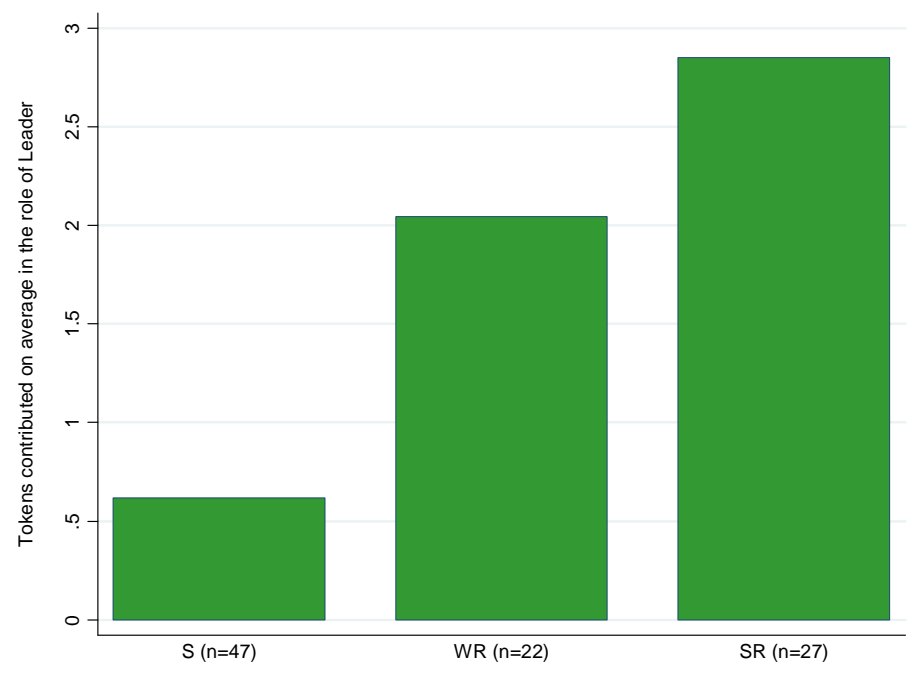

Regression analysis of Leaders' contributions decisions on a set of dummy variables identifying the three Leader types shows that the results are substantially robust to a set of controls for individual and session effects (Table I). Models I to IV build incrementally including personal characteristics (Model II onwards), controls for session effects (Model III) and for the reliability of questionnaire answers (Model IV, where subjects whose answers to the questionnaire are selfreportedly unreliable are removed from the sample ${ }^{10}$ ). SR Leaders' contributions exceed S Leaders' contributions by about two tokens in all regression models and the difference is always significant at the 1\% level. WR Leaders also contribute about 1 token more than S Leaders and the difference is highly significant in all models. There is also marginal evidence that WR and SR Leaders contribute different amounts (we can reject the null hypothesis of equal contributions either at the $5 \%$ or $10 \%$ level depending on the regression model specification).

Among the variables controlling for individual characteristics, the dummy identifying subjects studying Economics is highly significant in all the regression models where it is included: Leaders who study Economics appear to contribute significantly less than others. This result is consistent with findings from other laboratory experiments (e.g. Marwell and Ames (1981); Frank,

\footnotetext{
10 The last question in the post-experimental questionnaire asked subjects to report whether we could rely on their answers to the questionnaire on a scale from 1 (very unreliable answers) to 9 (very reliable answers). Model IV excludes from the sample 4 subjects who scored 1 on this reliability scale.
} 
et al. (1993)), although there is an ongoing debate about the reasons for these differences in otherregarding behaviour (see, e.g., Frey and Meier (2003)).

Consistent with the findings by Arbak and Villeval (2007), male Leaders seem to contribute more than female Leaders, but the difference is only significant at the $5 \%$ level in Model IV when we exclude from the sample subjects who gave very unreliable answers to the questionnaire.

Table 1. Determinants of Leader Contributions ${ }^{11}$

\begin{tabular}{|c|c|c|c|c|}
\hline & I & II & III & IV \\
\hline 1 if SR & $\begin{array}{l}2.235^{* * *} \\
(0.345)\end{array}$ & $\begin{array}{l}2.078^{* * *} \\
(0.363)\end{array}$ & $\begin{array}{l}1.928^{* * *} \\
(0.383)\end{array}$ & $\begin{array}{l}2.014^{* * *} \\
(0.363)\end{array}$ \\
\hline 1 if WR & $\begin{array}{l}1.428^{* * *} \\
(0.320)\end{array}$ & $\begin{array}{l}1.391^{* * *} \\
(0.295)\end{array}$ & $\begin{array}{l}1.188^{* * *} \\
(0.338)\end{array}$ & $\begin{array}{l}1.305^{* * *} \\
(0.314)\end{array}$ \\
\hline 1 if Male & & $\begin{array}{c}0.275 \\
(0.266)\end{array}$ & $\begin{array}{c}0.402 \\
(0.292)\end{array}$ & $\begin{array}{l}0.572^{* *} \\
(0.285)\end{array}$ \\
\hline 1 if Area of Study is Economics & & $\begin{array}{c}-0.839^{* * *} \\
(0.259)\end{array}$ & $\begin{array}{c}-0.876^{* * *} \\
(0.281)\end{array}$ & $\begin{array}{c}-0.848^{* * *} \\
(0.283)\end{array}$ \\
\hline Machiavellian score & & $\begin{array}{l}-0.021^{* *} \\
(0.010)\end{array}$ & $\begin{array}{c}-0.021^{* *} \\
(0.010)\end{array}$ & $\begin{array}{l}-0.018^{*} \\
(0.010)\end{array}$ \\
\hline Number of Friends in Session & & & $\begin{array}{c}-0.507^{* *} \\
(0.238)\end{array}$ & $\begin{array}{l}-0.481^{*} \\
(0.247)\end{array}$ \\
\hline Constant & $\begin{array}{c}0.617^{* * *} \\
(0.180)\end{array}$ & $\begin{array}{l}2.803^{* * *} \\
(1.052)\end{array}$ & $\begin{array}{c}2.887^{* * *} \\
(1.072)\end{array}$ & $\begin{array}{l}2.560^{* *} \\
(1.033)\end{array}$ \\
\hline Session dummies & No & No & Yes & Yes \\
\hline Unreliable answers excluded & No & No & No & Yes \\
\hline$N$. & 96 & 96 & 96 & 92 \\
\hline F-statistic & $F(2,93)=24.55$ & $F(5,90)=19.72$ & $F(11,84)=11.56$ & $F(11,80)=11.08$ \\
\hline $\begin{array}{l}\text { Prob }>F \\
R^{2}:\end{array}$ & $\begin{array}{l}0.000 \\
0.360\end{array}$ & $\begin{array}{l}0.000 \\
0.447\end{array}$ & $\begin{array}{l}0.000 \\
0.489\end{array}$ & $\begin{array}{l}0.000 \\
0.527\end{array}$ \\
\hline
\end{tabular}

OLS regressions. Dependent variable is Leader's contribution. Robust standard errors in parentheses.

* $.05 \leq p \leq .10 ; * * .01 \leq p<.05$; *** $p<.01$.

The coefficient of the Machiavellian instrument is negative and statistically significant: Leaders with high Machiavellian scores tend to contribute less than those who score low in Machiavellianism, a result that could be due to the fact that the former may be more pessimistic about Followers' reciprocity because of their inherently cynical view of human nature. This result is consistent with Burks, et al. (2003) who also find that first movers with a high Machiavellian score send less in a trust game where subjects played both roles, but contrasts the findings of

\footnotetext{
${ }^{11}$ Long (1997) (pp. 115-119) discusses the costs and benefits of using a linear regression model (LRM) instead of ordered regression models (ORM) when using ordinal dependent variables and concludes that in general “...the results of the LRM only correspond to those of the ORM if [the cut-points of an ORM] are all about the same distance apart" (p. 119), i.e. if the intervals between adjacent categories of the dependent variable are equal, which is in fact the case for the variable "Leader's contribution”. Given their simpler interpretation, OLS estimates are reported hereafter. Any inference based on such estimates can be also derived using an ORM estimation.
} 
Gunnthorsdottir, et al. (2002) who show that the Machiavellian score is not a good predictor for sending behaviour in trust games ${ }^{12}$.

Model III and IV control for session effects and include session dummies (which are all jointly insignificant in both models) and the variable "Number of Friends in Session" measuring the number of persons known to the subject who are also participating to the session. Although the overwhelming majority of participants were strangers to one another (on average a participant only knew 0.12 other participants), knowing other participants in the session reduces the amount a Leader is willing to contribute.

Overall, our main results are substantially robust to these controls as well as to the exclusion from the subject pool of those subjects who submitted unreliable answers to the post-experimental questionnaire.

\subsection{Are Strong Reciprocators better Leaders because they are more optimistic about Followers?}

So far we have shown that subjects' cooperation preferences, as measured by their conditional contribution decisions, strongly correlate with their leader-contributions: reciprocal Leaders contribute significantly more than self-interested Leaders.

However, the large difference in leader-contribution decisions between SR, WR and S subjects that we observed in our experiment may not necessarily be due to differences in the underlying social motivations of these three types. SR, WR and S subjects may instead hold different expectations about the Follower's behaviour, which may in turn drive their contribution decisions. For example, $\mathrm{S}$ subjects may tend to believe that Followers are most likely to behave as an "S type" and hence contribute nothing to the project irrespective of the Leader's contribution, while SR subjects may believe that free-riding behaviour is relatively less common and hence may expect a positive return from contributing to the project. Such a systematic bias in beliefs (and in particular the tendency to estimate one's own behaviour to be more common than it is estimated by those who engage in alternative behaviours) is called the false consensus effect (Ross, et al. (1977)). ${ }^{13}$

\footnotetext{
12 The average score in the whole sample was 98.92 (s.d. 14.11), which is similar to that reported in other experimental studies (e.g. Gunnthorsdottir, et al. (2002); Burks, et al. (2003); Carpenter, et al. (2005b); Flues and Gächter (2008)). Higher Machiavellian scores are also generally associated with less generous offers in dictator games, but not in ultimatum games (see, e.g. Carpenter, et al. (2005b); Carpenter, et al. (2005a); Spitzer, et al. (2007)). Meyer (1992) shows that subjects scoring low on the Machiavellian instrument are more likely to reject unfair offers in a one-shot ultimatum game with hypothetical payoffs. Lastly, Gunnthorsdottir, et al. (2002) find that the Machiavellian score is instead a good predictor of reciprocal behaviour, but Burks, et al. (2003) fail to replicate this result. We also cannot reject the hypothesis that the Machiavellian score is the same across S, SR and WR subjects (Kruskal-Wallis test: $\left.\chi^{2}(2 d . f)=0.009,. p<0.996\right)$, suggesting that the measurement is poorly correlated with reciprocal behaviour.

${ }^{13}$ In the context of cooperation a seminal paper is Kelley and Stahelski (1970). For a discussion about whether the consensus effect is "truly” false see Engelmann and Strobel (2000).
} 
To verify whether a false consensus effect might be driving our results, we start by exploring the relation between subjects' own preferences and their expectations about the cooperation preferences of their opponents, as elicited in the Prediction Task.

As a first step in Figure 3 we draw - both separately for each preference type and aggregated across types - the average conditional contribution decisions that subjects predicted the other person in their group would have made in the role of Follower.

Figure 3. Average Predicted Follower Contribution

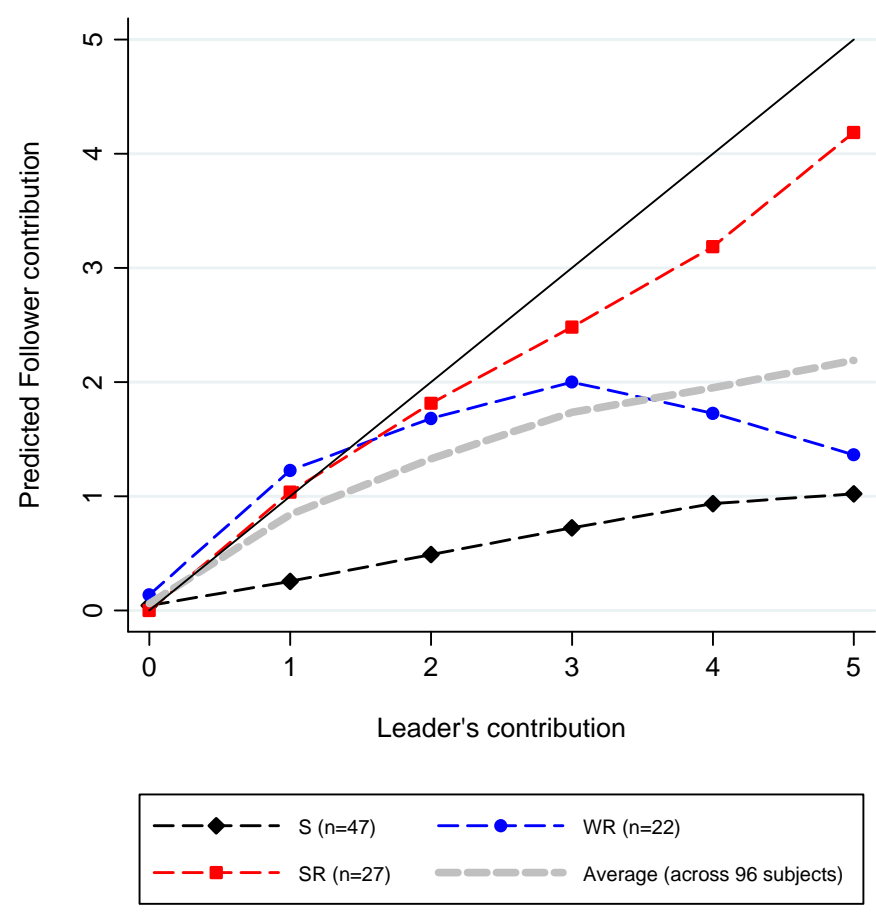

The most remarkable feature of Figure 3 is its similarity with Figure 1, where we depicted subjects' average own contribution decisions by cooperation type. SR and WR contribution decisions are almost identical to their beliefs about others' contribution decisions. S subjects' predictions of others' contribution decisions differ instead from their own contribution decisions, as these subjects seem to believe that other's contributions increase in the Leader's contribution decisions whereas they always chose to contribute nothing irrespective of the Leader's decision.

Overall, Figure 3 suggests that different cooperation types hold different beliefs about others' cooperation types. To explore this issue further, we use subjects' predictions about their opponent's conditional contributions to infer the type of Follower they believe they are most likely to be matched with. That is, if a subject predicts that the opponent will contribute nothing to the project irrespective of the leader-contribution, we conclude that that subject believes he or she is most likely matched with a Selfish opponent, S. On the other hand, if a subject's predictions are such that his or her best response as a Leader to the opponent's predicted strategy as a Follower is 
to contribute everything to the project, we conclude that the subject must believe he or she is matched with a Follower who is a Strong Reciprocator, SR. ${ }^{14}$ If instead a subject's best response to his or her own predictions would induce him or her to contribute some, but not all, of the endowment to the project, then we conclude that the subject believes he or she is matched with a Weak Reciprocator, WR. Lastly, if a subject finds it optimal to contribute nothing to the project even if he or she believes that the opponent will in fact contribute positive amounts in response to some leader-contributions, we conclude that the subject believes he or she is matched with a NonReciprocator NR.

Figure 4 shows - separately for each preference type - the proportion of Leaders who believe they are matched with an S, WR, SR or NR Follower.

Figure 4. Proportions of Predicted Follower Type by each Type of Leader

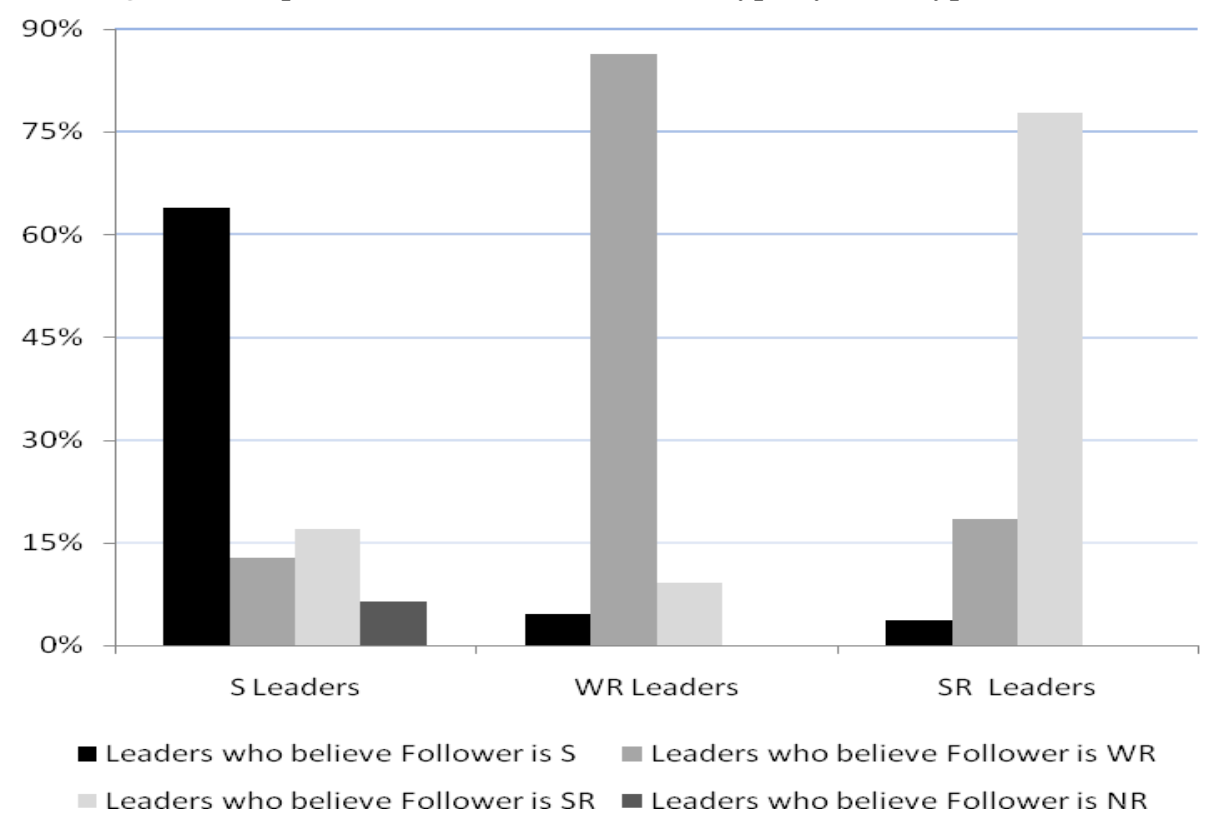

Clearly, subjects' expectations of others' preferences are strongly biased towards their preference type: more than $60 \%$ of S Leaders believe that they are matched with an S Follower, more than $80 \%$ of WR Leaders believe they are matched with a WR Follower, whereas almost $80 \%$ of SR Leaders think the person they are matched with is also a SR type. We can strongly reject the hypothesis that the distribution of predicted cooperation types is the same across the three Leader types: $\chi^{2}(6 d . f)=81.11,. p<0.001$. Pair-wise Fisher exact tests performed separately for each preference type are all significant at the $1 \%$ level.

So far we have shown that our subjects' predictions about others' preference types are consistent with a false consensus effect. Our next step is to explore whether such consensus effect is actually driving our results about differences in leader-contributions across preference types. It

\footnotetext{
${ }^{14}$ Paralleling how we classify subjects' cooperation types, should the subject be indifferent between two or more best responses we use the largest contribution decision.
} 
may be that differences in cooperation preferences are not the reason why SR subjects contribute more than S subjects in the role of leader. Instead, SR subjects may choose to make larger leadercontributions than S subjects because they think it more likely that Followers will reciprocate positive contributions. If this is in fact the case, we would then expect that, for a given belief about the opponent's type, leader-contributions would not be significantly different across Leader's preference types.

Ideally, we would like to compare whether S Leaders who believe that Followers are SR types contribute different amounts from SR Leaders who also believe than Followers are SR types, and so on. Unfortunately, the number of observations underlying some of the cells in our crosstabulation of Leader's preference types against the Leaders' predictions of the opponent's preference type does not allow us to make such comparisons in a meaningful way. For example, there are only $8 \mathrm{~S}$ Leaders who believe that the Follower they are matched with is a SR type and only 1 SR Leader who believes his or her opponent is an S type.

Therefore, we slightly modify the classification we have introduced above and combine in a unique category those Leaders who believe they are matched with either a SR or a WR opponent. Because these Leaders believe that contributing positive amounts to the project does yield (weakly) better returns than contributing nothing, we call them “Optimists”. Similarly, Leaders who believe that contributing nothing to the project yields the highest earnings (i.e. Leaders who believe that they are matched with either S or NR Followers) are called "Pessimists".

Figure 5 shows - separately for each preference type - the proportion of Leaders who are Optimist and Pessimists. Obviously, the majority of S Leaders are Pessimists while most of Leaders who are either WR or SR are classified as Optimists.

Figure 5. Proportions of Pessimistic/Optimistic Leaders

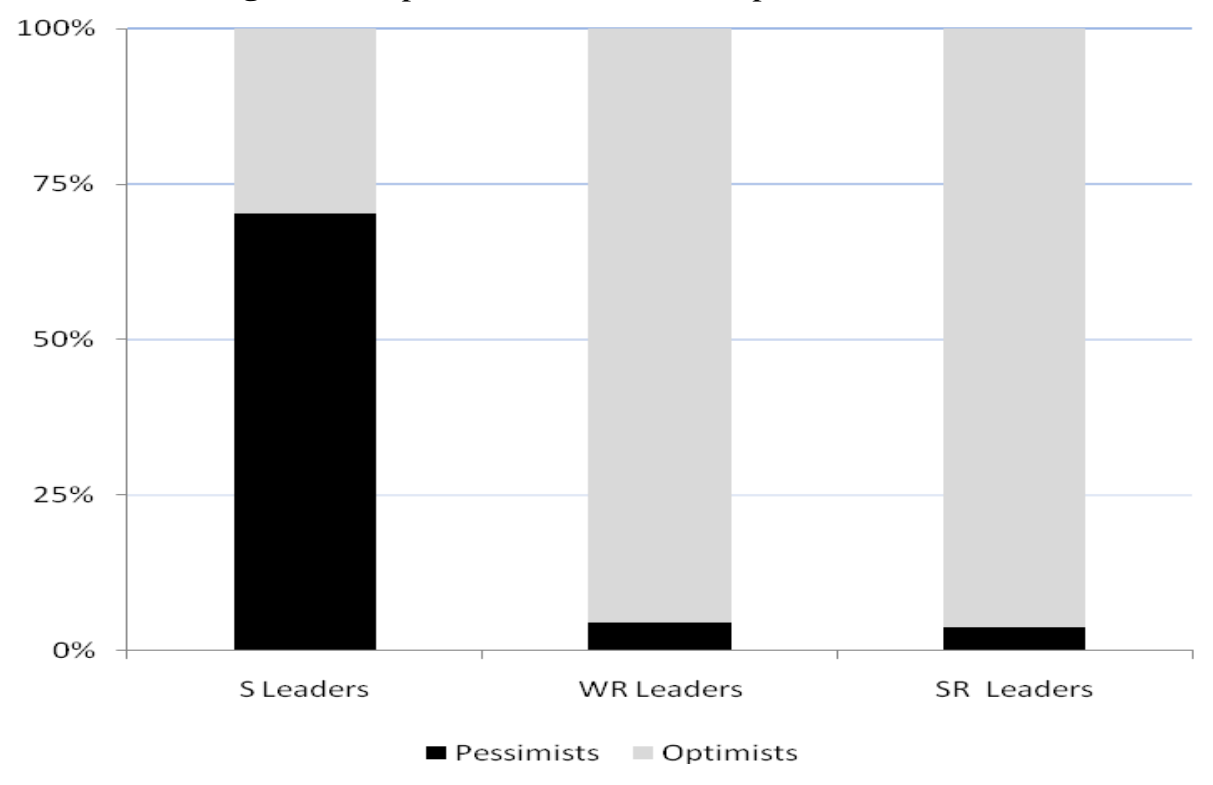


We now have a sufficient number of observations in the Optimists category to make meaningful comparisons between the contributions of Leaders who have different cooperation preferences but hold the same degree of optimisms about their opponent's preferences.

Table 2 reports the average contribution levels of S, WR and SR Leaders who have optimistic beliefs about their opponent's preferences. Although optimistic S Leaders make relatively larger contributions to the project (about 1.3 tokens, roughly 1 token more than pessimistic S Leaders), a Kruskal-Wallis test allows us to reject the hypothesis that optimistic Leaders make similar contributions irrespective of their preference type $\left(\chi^{2}(2 d . f)=10.29,. p=0.006\right)$. Pair-wise Mann-Whitney-U-tests reveal that $\mathrm{S}$ Leaders' contributions differ significantly from SR Leaders' contributions $(z=2.896, p=0.004)$, while there is only marginal evidence that S and WR Leaders contribute different amounts to the project $(z=1.732, p=0.083)$. There is also evidence that SR and WR Leaders' contributions are significantly different $(z=2.012, p=0.044)$.

Table 2: Optimistic Leaders’ Contributions

\begin{tabular}{l|c}
\hline \multicolumn{2}{c}{ Table 2: Optimistic Leaders' Contributions } \\
\hline & Average contribution (s.d.) \\
\hline S Leaders $(n=14)$ & $1.29(1.49)$ \\
WR Leaders $(n=21)$ & $2.00(1.26)$ \\
SR Leaders $(n=26)$ & $2.77(1.50)$ \\
\hline \hline
\end{tabular}

It could be argued that the "degree” of optimism of optimistic S Leaders might differ from the "degree" of optimism of optimistic WR and SR Leaders: for example, S Leaders who believe they are matched with a reciprocator might systematically underestimate his or her degree of reciprocity relative to WR and SR Leaders. Such variation is not accounted for when we make comparisons between Leaders that have different cooperation types but fall into the same broad category "Optimists".

To control for these possible differences in the degree of optimism of S, WR and SR Leaders, we run a regression of Leaders' contributions decisions on a set of dummy variables identifying the Leader's cooperation type and on a variable measuring the Leader's best-response to his or her own predictions about the opponent's conditional contribution decisions. The higher the Leader's best-response to his or her own beliefs, the more optimistic he or she is about the strength of the reciprocal preferences of their opponent. Hence we call this variable "Degree of 
Optimism”. The results of the regression (which uses the specification introduced earlier in Model II and reported in Table 1) are shown in Table 3.

Table 3: Leader Contribution and Degree of Optimism

\begin{tabular}{l|c}
\hline \hline & \\
\hline 1 if SR & $1.140^{* *}$ \\
& $(0.486)$ \\
1 if WR & $0.972^{* *}$ \\
& $(0.464)$ \\
Degree of Optimism & $0.204^{*}$ \\
& $(0.118)$ \\
1 if Male & 0.523 \\
& $(0.332)$ \\
1 if Area of Study is Economics & $-1.323^{* * *}$ \\
& $(0.402)$ \\
Machiavellian score & -0.018 \\
& $(0.012)$ \\
Constant & 2.419 \\
& $(1.571)$ \\
\hline & 61 \\
Prob $>F$ & $F(6,54)=6.69$ \\
$R^{2}$ & 0.000 \\
\hline \hline Dependent variable is the optimistic Leader's contribution. Robust \\
standard errors in parentheses.
\end{tabular}

The variable "Degree of Optimism" is (weakly) significant and positive: Leaders whose best-response to their own expectations is higher tend to contribute more to the project. Nevertheless, for a given degree of optimism, SR Leaders and WR Leaders contribute significantly more than S Leaders (both coefficients are positive and significantly different from zero at the $5 \%$ level). Hence, Leaders with the same degree of optimism do make different contributions depending on their preference type. ${ }^{15}$

Overall, these results show that Leaders' expectations about their opponent's preference type are systematically biased towards their own preference type (i.e. they are influenced by a false consensus effect). However, the large differences in leader-contribution decisions between SR, WR and S subjects that we observed in our experiment cannot be entirely explained in terms of systematic differences in expectations about others' preference types, because for a given belief about the opponent's type, leader-contributions are still significantly different across Leader's preference types.

\footnotetext{
${ }^{15}$ Note also that the effect of Machiavellianism is weakened by the inclusion of the variable "Degree of Optimism" which absorbs some variation in the amount contributed. This reinforces our explanation that the differences in contributions between subjects who score high and low on the Machiavellian scale might be due to the fact that because of their inherent cynical view of human nature the former are more pessimistic about Followers' reciprocity than the latter.
} 


\section{Discussion \& Conclusions}

We examine how social preferences and beliefs about the social preferences of others affect leadership contributions in a simple Leader-Follower game. The game uses the same type of earnings functions used in experiments examining voluntary contributions to a public good. Thus, a Follower's contribution increases group earnings at the expense of the Follower's narrow personal interests. Our experiment allows Leaders to attempt to induce such group-oriented behaviour through 'leading-by-example': by contributing Leaders might, if the Follower is sufficiently reciprocal, induce the Follower to contribute as well. Our focus is on the extent to which the leader's willingness to lead-by-example depends on her own social preferences, her beliefs about the social preferences of her Follower, and other personal characteristics.

As in previous experiments we find that many Followers are willing to reciprocate the Leader's contribution. About half of our subjects reciprocate to the extent that it pays for a selfinterested Leader to contribute something, and about half of these reciprocators are classified as "Strong Reciprocators", reciprocating to the extent that a self-interested Leader should contribute their entire endowment. In the role of Leader, however, Selfish subjects contributed very little: only $12 \%$ of their endowments. Strong Reciprocators contributed significantly more in the role of Leader: around 57\% of their endowments. Part of this effect can be explained by a variety of subjects' personal characteristics. Economists contribute less as Leaders, as do females, as do those who are more 'Machiavellian'. However, even after controlling for personal characteristics there is a large gap between the Leader contributions of Selfish and Strong Reciprocator subjects, roughly $40 \%$ points of endowments.

Our finding that Strong Reciprocators make higher Leader contributions than Selfish subjects is in line with recent studies from trust games where subjects play both roles. For example Altmann, et al. (2008) and Chaudhuri and Gangadharan (2007) both find that trustees who reciprocate more are more trusting. We see two main differences between trust games and our leader-follower game. First in our game the follower's decision affects group earnings, whereas in a trust game the follower's decision is a pure transfer, only affecting the distribution of group earnings. Second in our game the leader and follower have identical choice sets and earnings functions, and so the leader's decision can be easily viewed as an 'example' to the follower. In the trust game there is an asymmetry between roles that goes beyond the sequential structuring of choices, and this asymmetry makes it less clear that the trustor can 'lead by example'.

Altmann, et al. (2008) speculate that a 'false consensus' effect, whereby selfish subjects believe others are selfish and reciprocal subjects believe others are reciprocal, could explain why reciprocal trustees trust more in their experiment. The same effect may also explain why Strong 
Reciprocators make higher Leader contributions in our experiment. Our design allows us to control for differences in beliefs, and we do indeed find a strong correlation between Followertype and beliefs about the Follower-type of others: Strong Reciprocators believe that they will be paired with another Strong Reciprocator, whereas Selfish subjects believe they will be paired with another Selfish subject. However, even controlling for differences in beliefs about Follower responses, Strong Reciprocators contribute 23\% points more of their endowment than Selfish Leaders. Thus, differences in beliefs can only explain part of the difference between the Leader contributions of Selfish and Strong Reciprocator types and most of the difference reflects their differing social motivations. These findings are also consistent with those of Vyrastekova and Garikipati (2005), who correlate trustor decisions with their beliefs about the trustee's decision and with their distributional preferences as measured using a ring test. They find strong relation between distributional preferences and trustor decisions even after controlling for beliefs. They also find that beliefs are strongly correlated with distributional preferences.

To the extent that a large part of the variation in Leader contributions can be explained by cooperation preferences, even after controlling for beliefs, this suggests that groups will perform better when led by individuals who are willing to sacrifice personal benefit for the greater good. Further, since beliefs are highly correlated with cooperation preferences, such individuals are more likely to have optimistic views about Followers that will reinforce their contribution. While selfinterested Leaders could, in principle, do anything that an optimistic reciprocator does, their cooperation preferences and expectations about others make them less likely to provide effective leadership. 
Appendix: Experimental Instructions

\section{Instructions}

\section{General}

Welcome! You are about to take part in a decision-making experiment. It is important that you do not talk to any of the other participants until the experiment is over. If you have a question at any time, raise your hand and a monitor will come to your desk to answer it.

In this experiment you will be randomly paired with another person in this room. The amount you earn will depend on your decisions and the decisions of the person you are paired with. You will not learn the identity of the person you are paired with, neither during nor after today's session. You will be paid in private and in cash at the end of the experiment.

\section{The Basic Decision Situation}

The basic decision situation is simple. In each pair one person is designated as the "FIRST MOVER" and the other as the "SECOND MOVER". Each person is endowed with five tokens. The FIRST MOVER first decides how many of his or her tokens to contribute to a joint project. The SECOND MOVER is then informed of the FIRST MOVER's decision. The SECOND MOVER then decides how many of his or her tokens to contribute to the project.

Earnings depend on the decisions as follows.

For each token contributed to the project, the FIRST MOVER and the SECOND MOVER get $£ 1$ each.

For each token a person does not contribute to the project, that person gets $£ 1.50$.

So that everyone understands how choices translate into earnings we will give an example and a test. (The allocations of tokens used for the example and test are simply for illustrative purposes. In the experiment the allocations will depend on the actual choices of the participants.)

Example: Suppose the FIRST MOVER contributes 2 tokens to the project, and the SECOND MOVER contributes 4 tokens to the project. Thus in total 6 tokens are contributed to the project.

The FIRST MOVER will earn $6 \times £ 1=£ 6$ from the project and $3 \times £ 1.50=£ 4.50$ from the 3 tokens he or she has not contributed to the project. Thus, the FIRST MOVER's total earnings will be $£ 6+£ 4.50=£ 10.50$. 
The SECOND MOVER will earn $6 \times £ 1=£ 6$ from the project and $1 \times £ 1.50=£ 1.50$ from the 1 token he or she has not contributed to the project. Thus, the SECOND MOVER's total earnings will be $£ 6+£ 1.50=£ 7.50$.

Test: Before we continue with the instructions we want to make sure that everyone understands how their earnings are determined. Please answer the questions below. After a few minutes a monitor will check your answers. When everyone has answered the questions correctly we will continue with the instructions. Raise your hand if you have a question.

1. Suppose the FIRST MOVER contributes 5 tokens to the project, and the SECOND MOVER contributes 5 tokens to the project. Thus, in total 10 tokens are contributed to the project.

* How much will the FIRST MOVER earn from the project?

* How much will the FIRST MOVER earn from the tokens he or she does not contribute to the project?

* How much will the FIRST MOVER earn in total?

* How much will the SECOND MOVER earn from the project?

* How much will the SECOND MOVER earn from the tokens he or she does not contribute to the project?

* How much will the SECOND MOVER earn in total?

2. Suppose the FIRST MOVER contributes 0 tokens to the project, and the SECOND MOVER contributes 0 tokens to the project. Thus, in total 0 tokens are contributed to the project.

* How much will the FIRST MOVER earn from the project?

* How much will the FIRST MOVER earn from the tokens he or she does not contribute to the project?

* How much will the FIRST MOVER earn in total?

* How much will the SECOND MOVER earn from the project?

* How much will the SECOND MOVER earn from the tokens he or she does not contribute to the project?

* How much will the SECOND MOVER earn in total?

3. Suppose the FIRST MOVER contributes 1 token to the project, and the SECOND MOVER contributes 4 tokens to the project. Thus, in total 5 tokens are contributed to the project.

* How much will the FIRST MOVER earn from the project?

* How much will the FIRST MOVER earn from the tokens he or she does not contribute to the project?

* How much will the FIRST MOVER earn in total?

* How much will the SECOND MOVER earn from the project? 
* How much will the SECOND MOVER earn from the tokens he or she does not contribute to the project?

* How much will the SECOND MOVER earn in total?

\section{How You Make Decisions}

You will make decisions on the computer by completing a screen. The attached sheet shows what the screen will look like. We want to know what you would do in the role of the FIRST MOVER and what you would do in the role of the SECOND MOVER. Thus you will be prompted to make decisions in both roles. Only after you have made your decisions will the computer inform you of your actual role, "FIRST MOVER" or "SECOND MOVER", and this will determine your relevant decisions for calculating earnings. The computer will select roles randomly: there is a $50 \%$ chance you will be the FIRST MOVER and the person you are paired with will be the SECOND MOVER, and a 50\% chance you will be the SECOND MOVER and the person you are paired with will be the FIRST MOVER.

DECISION TASK 1: In the first blank field you must enter your contribution decision in the role of the FIRST MOVER. You simply indicate how many tokens to contribute to the project. You can enter any whole number from 0 to 5 inclusive.

DECISION TASK 2: The next set of blank fields is for your contribution decision in the role of the SECOND MOVER. We want to know what you as SECOND MOVER would do for any contribution that the FIRST MOVER might make. That is, we want to know:

- what you would do if the FIRST MOVER contributed zero tokens to the project,

- what you would do if the FIRST MOVER contributed one token,

- what you would do if the FIRST MOVER contributed two tokens, etc.

Thus the SECOND MOVER will be prompted to make a decision for every possible contribution by the FIRST MOVER. The relevant decision will be determined by the FIRST MOVER's actual contribution. If the FIRST MOVER contributed zero tokens to the project, the SECOND MOVER's contribution will be the number he or she types in the first box. If the FIRST MOVER contributed one token to the project, the SECOND MOVER's contribution will be the number he or she types in the second box, and so on. In each box you can enter any whole number from 0 to 5 inclusive.

The screen also has a final set of blank fields for a PREDICTION TASK. Here you must enter a prediction about what the other person enters for DECISION TASK 2. 
Once you have completed the decision and prediction tasks you should click on the "Submit" button. You will then be prompted to either change or confirm your decisions and predictions. At this point, if you want to you will be able to go back and change your entries. Once you confirm your decisions and predictions you cannot change them. When everyone in the room has submitted and confirmed their decisions and predictions earnings will be calculated.

\section{How Your Cash Earnings Are Determined}

First you will be informed of whether you are the FIRST MOVER or the SECOND MOVER. The computer then determines contributions from decisions as follows.

If you are the FIRST MOVER your contribution is determined by what you entered in DECISION TASK 1 . The other person's contribution is determined by what they entered in DECISION TASK 2 in the box corresponding to your contribution.

If you are the SECOND MOVER the other person's contribution is determined by what they entered in DECISION TASK 1. Your contribution is determined by what you entered in DECISION TASK 2 in the box corresponding to the other person's contribution.

From these contributions earnings are calculated. For each token you do not contribute to the project you get $£ 1.50$ and for each token contributed to the project the FIRST MOVER and the SECOND MOVER get $£ 1$ each.

\section{Bonus Earnings}

In addition, you can earn money from correctly predicting what the other person enters for DECISION TASK 2. Your predictions in the PREDICTION TASK will be compared with what the person you are matched with actually did in DECISION TASK 2. For each correct prediction you will receive 50p.

\section{Beginning the Experiment}

Note: in this experiment you will complete ONLY ONE screen. After you submit your entries you will be prompted to confirm them. At this point, if you want to you will be able to change your entries. Once you confirm your entries you cannot change them, and these will be used for determining earnings. If you have a question at any time please raise your hand and a monitor will come to your desk to answer it. Now, please look at your computer screen and begin making your decisions and predictions. 


\section{The Decision Screen}

\section{DECISION TASK 1 - Suppose you are the FIRST MOVER:}

Choose how many tokens YOU want to contribute to the project.

How many tokens do YOU want to contribute to the project?

\section{DECISION TASK 2 - Suppose you are the SECOND MOVER:}

Choose how many tokens YOU want to contribute to the project for each possible contribution decision of the FIRST MOVER

\begin{tabular}{|l|l|l|l|l|l||}
\hline The FIRST MOVER contribution to the project: & $\mathbf{0}$ & $\mathbf{1}$ & $\mathbf{2}$ & $\mathbf{3}$ & $\mathbf{4}$ \\
\hline YOUR contribution to the project: & & & & & \\
\hline
\end{tabular}

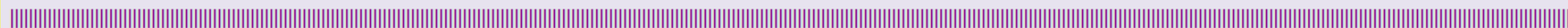

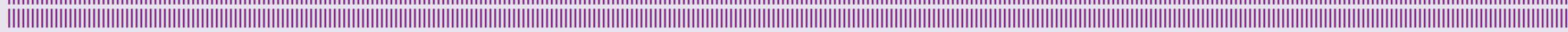

\section{PREDICTION TASK:}

Predict how the person you are matched with has filled out DECISION TASK 2.

\begin{tabular}{|l|l|l|l|l|l|}
\hline The FIRST MOVER contribution to the project: & $\mathbf{0}$ & $\mathbf{1}$ & $\mathbf{2}$ & $\mathbf{3}$ & $\mathbf{4}$ \\
\hline $\begin{array}{l}\text { YOUR prediction of the OTHER PERSON's most likely contribution to } \\
\text { the project: }\end{array}$ & & & & & \\
\hline
\end{tabular}

In each box you can enter any whole number from 0 to 5 inclusive 


\section{References}

Altmann, S., Dohmen, T., Wibral, M., 2008. Do the reciprocal trust less? Economics Letters 99, 454-457.

Arbak, E., Villeval, M.-C., 2007. Endogenous leadership: selection and influence. IZA Discussion Paper No. 2732, Institute for the Future of Labor, Bonn.

Blanco, M., Engelmann, D., Koch, A. K., Normann, H.-T., 2008. Belief elicitation in experiments: is there a hedging problem? IZA Discussion Paper No. 3517, Institute for the Future of Labor, Bonn.

Burks, S. V., Carpenter, J. P., Verhoogen, E., 2003. Playing both roles in the trust game. Journal of Economic Behavior \& Organization 51, 195-216.

Carpenter, J., Verhoogen, E., Burks, S. V., 2005a. The effect of stakes in distribution experiments. Economic Letters 86, 393-398.

Carpenter, J. P., Burks, S., Verhoogen, E., 2005b. Comparing students to workers: The effect of stakes, social framing, and demographics on bargaining outcomes. In Carpenter, J. P., et al., (Eds.), Field Experiments in Economics. Research in Experimental Economics. Elsevier JAI, Amsterdam.

Chaudhuri, A., Gangadharan, L., 2007. An experimental analysis of trust and trustworthiness. Southern Economic Journal 73, 959-985.

Christie, R., Geis, F. L., 1970. Studies in Machiavellianism. Academic Press, New York and London.

Clark, K., Sefton, M., 2001. The sequential prisoner's dilemma: evidence on reciprocation. Economic Journal 111, 51-68.

Drucker, P. F., 2004. The Daily Drucker: 366 Days of Insight and Motivation for Getting the Right Things Done. Collins Business, New York.

Engelmann, D., Strobel, M., 2000. The false consensus effect disappears if representative information and monetary incentives are given. Experimental Economics 3, 241-260.

Fischbacher, U., 2007. z-Tree: Zurich toolbox for readymade economic experiments. Experimental Economics 10, 171-178.

Fischbacher, U., Gächter, S., Fehr, E., 2001. Are people conditionally cooperative? Evidence from a public goods experiment. Economics Letters 71, 397-404.

Flues, F., Gächter, S., 2008. Machiavellian cooperators and punishers. mimeo, University of Nottingham.

Frank, R. H., Gilovich, T., Regan, D. T., 1993. Does studying economics inhibit cooperation? Journal of Economic Perspectives 7, 159-171.

Frey, B. S., Meier, S., 2003. Are political economists selfish and indoctrinated? Evidence from a natural experiment. Economic Inquiry 41, 448-462.

Gächter, S., Renner, E., 2003. Leading by example in the presence of free rider incentives. paper presented at a Conference on Leadership, March 2003, Lyon.

Gächter, S., Renner, E., 2006. The effects of (incentivized) belief elicitation in public good experiments. CeDEx Discussion Paper No. 2006-16, University of Nottingham.

Gächter, S., Renner, E., 2007. The role of leadership and beliefs in the voluntary provision of public goods. mimeo, University of Nottingham.

Greiner, B., 2004. An Online Recruitment System for Economic Experiments. In Kremer, K., Macho, V., (Eds.), Forschung und wissenschaftliches Rechnen GWDG Bericht 63. Gesellschaft für Wissenschaftliche Datenverarbeitung, Göttingen, pp. 79-93. 
Güth, W., Levati, M. V., Sutter, M., Van der Heijden, E., 2007. Leading by example with and without exclusion power in voluntary contribution experiments. Journal of Public Economics 91, 1023-1042.

Gunnthorsdottir, A., McCabe, K., Smith, V., 2002. Using the Machiavellianism instrument to predict trustworthiness in a bargaining game. Journal of Economic Psychology 23, 49-66.

Kelley, H., Stahelski, A., 1970. Social interaction basis of cooperators' and competitors' beliefs about others. Journal of Personality and Social Psychology 16, 190-219.

Keser, C., van Winden, F., 2000. Conditional cooperation and voluntary contributions to public goods. Scandinavian Journal of Economics 102, 23-39.

Levati, M. V., Sutter, M., van der Heijden, E., 2007. Leading by example in a public goods experiment with heterogeneity and incomplete information. Journal of Conflict Resolution 51, 793-818.

Long, S. J., 1997. Regression Models for Categorical and Limited Dependent Variables. SAGE Publications, Thousand Oaks, CA.

Marwell, G., Ames, R. E., 1981. Economists free ride, does anyone else? Experiments on the provision of public goods, IV. Journal of Public Economics 15, 295-310.

Meyer, H.-D., 1992. Norms and self-interest in ultimatum bargaining: The prince's prudence. Journal of Economic Psychology 13, 215-232.

Moxnes, E., van der Heijden, E., 2003. The effect of leadership in a public bad experiment. Journal of Conflict Resolution 47, 776-795.

Potters, J., Sefton, M., Vesterlund, L., 2007. Leading-by-example and signaling in voluntary contribution games: an experimental study. Economic Theory 33, 169-182.

Ross, L., Greene, D., House, P., 1977. The "false consensus effect": An egocentric bias in social perception and attribution processes. Journal of Experimental Social Psychology 13, 279301.

Selten, R., 1967. Die Strategiemethode zur Erforschung des eingeschränkt rationalen Verhaltens im Rahmen eines Oligopolexperimentes. In Sauermann, H., (Ed.), Beiträge zur experimentellen Wirtschaftsforschung. J.C.B. Mohr (Paul Siebeck), Tübingen, pp. 136168.

Spitzer, M., Fischbacher, U., Herrnberger, B., Gron, G., Fehr, E., 2007. The neural signature of social norm compliance. Neuron 56, 185-196.

Vyrastekova, J., Garikipati, S., 2005. Beliefs and trust: an experiment. CentER Discussion Paper No. 2005-88, University of Tilburg. 